\title{
POST STROKE DEPRESSION AND ANXIETY: PREVALANCE AND CORRELATES
}

\author{
NASMI NOUSHAD ${ }^{1 *}$, SACHITA ${ }^{2}$, SHILPA ANNA VARUGHESE ${ }^{2}$, SIJIMOL K JOY ${ }^{2}$, SNEHA JOSE ${ }^{2}$
}

${ }^{1}$ Bapuji Pharmacy College, Davangere, Karnataka, India. ${ }^{2}$ Department of Pharmacy Practice, Bapuji Pharmacy College and SSIMS and RC, Davangere, Karnataka, India. Email: nasmi.n92@gmail.com

Received: 25 May 2021, Revised and Accepted: 09 August 2021

ABSTRACT

Objectives: The objective of the study is to evaluate the prevalence of depression and anxiety in post-stroke patients and identify its predictors.

Materials and Methods: This study was conducted for a period of 6 months among 81 patients admitted with stroke in SSIMS and RC, Davangere. The information compiled from patient data collection form was assessed for comorbid conditions and type of stroke. Assessment for depression and anxiety was conducted using Hamilton D (HAM-D) and HAM-A scale and information of location of lesion was obtained from patient's neuroimaging results. Quality of life (QOL) of post-stroke was assessed using stroke and aphasia QOL (SAQOL) questionnaire. Follow-up was conducted for patients who were diagnosed with depression and anxiety within 1 to 3 months.

Results: Depression was more prevalent as compared to anxiety in post-stroke patients and was predominant in males and between the ages 61 and 70 years. Hypertension and diabetes were found to be a major comorbid conditions in such patients. Factors contributing to increased risk of depression and anxiety after stroke include age, sex, comorbidities, lesion location, and type of stroke. Post-stroke depression (PSD) and anxiety showed statistically significant association with left-sided lesion.

Conclusion: PSD and anxiety are a relatively common complications and can result in poor QOL in stroke patients. Early detection of depression and anxiety symptoms may assist functional recovery and improve QOL in stroke patients. Careful evaluation of PSD and post-stroke anxiety should be integrated into clinical care of stroke patients.

Keywords: Stroke, Post-stroke depression, Post-stroke anxiety, Quality of life, Hamilton Rating scale for depression, Hamilton rating scale for anxiety, Stroke and aphasia quality of life scale.

(C) 2021 The Authors. Published by Innovare Academic Sciences Pvt Ltd. This is an open access article under the CC BY license (http://creativecommons.org/ licenses/by/4.0/) DOI: http://dx.doi.org/10.22159/ajpcr.2021v14i9.42348. Journal homepage: https://innovareacademics.in/journals/index.php/ajpcr

\section{INTRODUCTION}

Post-stroke depression (PSD) and post-stroke anxiety (PSA) are common neuropsychiatric symptoms after stroke, with estimated prevalence rates between $40 \%$ and $30 \%$, respectively.

"Depression is a common mental disorder characterized by sadness, loss of interest in activities and by decreased energy" whereas "Anxiety is characterized by feelings of distress or worry, maladaptive thinking, perceived threat, and physiological arousal". The association of neuropsychiatric disorders with cerebrovascular disease includes depression, anxiety disorder, apathy, cognitive disorder, mania, psychosis, pathological affective display, catastrophic reactions, fatigue, and anosognosia. PSD occurs in a significant number of patients and constitutes an important complication of stroke, leading to greater disability as well as increased mortality Robert G Robinson et al [1].

Due to similarity in symptoms of depression and anxiety, anxiety is often misdiagnosed as depression itself Monica Vermani et al [2]. However, now there exists specific screening test for both anxiety and depression which can also be supported by various constructs from anatomical and neurobiological areas. Both PSD and PSA can significantly affect the recovery of the neurological function in patients with stroke, significantly reduce the quality of life (QOL) and increase the mortality EM Khedr et al [3].

Since the identification of PSD and PSA is a significant clinical problem, we evaluated the predictors that indicate patients at risk of developing PSD and PSA which include type of stroke, gender, QOL, etc. Early identification of PSD may improve the stroke outcomes and prevent psychiatric consequences Yihong Fang et al [4].

\section{METHODS}

A prospective observational study was conducted in SSIMS and RC (2019), a tertiary care teaching hospital, Davanagere, for a period of 6 months aiming to determine the incidence and correlates for PSD and PSA. Ethical approval for the study was obtained from the Institutional Ethics Committee of Bapuji Pharmacy College, Davanagere, Karnataka.A total of 81 patients were included in the study. Demographic details and Neuroimaging results were collected, and patients were evaluated at baseline and follow up for functional and cognitive deficits, PSD, PSA, and QOL after 3 months. Quantification of depression and anxiety was done by administration of Hamilton (HAM) A and HAM D scales. Patient's post-stroke QOL was quantified using stroke and aphasia QOL (SAQOL) questionnaire. Stroke severity was assessed using NIHSS scale and patient education was provided during the baseline. Collected data was then analyzed, significant variables associated within the data were identified by independent student t-test using SPSS 18.0 software. Descriptive characteristics among the groups were compared to check for deviations. Wilcoxon signed ranked test (2 independent samples) was employed to observe statistical significance between categories inaccuracy.A value of $p<0.05$ was considered significant. Descriptive analysis of baseline and follow-up data was conducted with the help of the Shapiro-Wilk test of normality. The summarized findings were rearranged and tabulated in a graphical and table form.

\section{RESULTS}

Among the 81 individuals enrolled in the study -54 (67\%) of males and 27 (33\%) of females suffered from stroke. Most of the subjects belong to the age group of $61-70$ years (42\%) Table 1. 
Among the study population, 69 (85\%) had hypertension, 41 (50.6\%) diabetes,18 (22\%) Ischemic heart disease (IHD), 12 (15\%) respiratory infections, and 9 (11\%) dyslipidaemia Table 2.

About $64(79 \%)$ patients had ischemic stroke and 17 (21\%) patients had hemorrhagic stroke Figure 1 and Table 3.

In view of lesion location, majority of the patients displayed a left hemispheric stroke followed by right and bilateral stroke Figure 2 and Table 4 .

Among 81 patients- 36 (44\%) patients showed significant symptoms of depression and $11(13 \%)$ showed significant symptoms of anxiety after stroke onset. Out of these $10(12 \%)$, patients had both depression and anxiety Figure 3 and Table 5 .

Among 36 patients showing the symptoms of depression-19 (23\%) patients showed mild depression, $10(12 \%)$ showed moderate depression, and 7 (9\%) patients severe depression Table 6.

Among 11 patients showing the symptoms of anxiety - 7 (6\%) patients showed mild anxiety, $2(3 \%)$ showed moderate anxiety, and $2(3 \%)$ patients' severe anxiety Table 7 .

The number of male patients was found to be more in the case of both post-stroke depressed and anxiety patients Figure 4 and Table 8 .

Among both post-stroke depressed and anxiety patients, the majority of them were found to have ischemic stroke Figure 5 and Table 9.

The effect of stroke type was assessed by comparison with respect to HAM D, HAM A, and SAQOL score. By conducting the Wilcoxon Signed rank test, it was known that there was significant positive effect of ischemic stroke type on the development of depression and anxiety and QOL of the patient $(\mathrm{p} \leq 0.05)$ Table $9 \mathrm{~b}$.

Among the post-stroke, depressed patients left-sided lesions were more predominant in all mild, moderate, and severe depression Figure 6 and Table 10.

Among the PSA patients left-sided lesions were more predominant in all mild, moderate, and severe anxiety Figure 7 and Table 11.

By comparison of scores within baseline of depression, anxiety, stroke severity, and aphasia; it was seen that aphasia has positive relation with the left location of lesion, but HAM D and HAM A scores did not show any significant relationship $(\mathrm{p} \leq 0.05)$ Table $11 \mathrm{~b}$.

Among the 81 stroke patients, the majority of them had moderate QOL followed by mild, normal, and severe based on the SAQOL scores Table 12.

Moderate QOL was predominant in post stroke depressed patients whereas severe SAQOL score is seen in PSA patients Figure 8 and Table 13.

SAQOL scores of baseline patients were compared with HAM D and HAM A to assess if any decline in QOL patients showed significant relation with depression and anxiety. The results of the test showed a positive effect to moderate QOL $(p \leq 0.05)$ Table 13b.

Among the 31 patients followed up, 8 (25\%) patients were found to be normal, 14 (45\%) with mild depression, 6 (19\%) with moderate, and 3 (9\%) with severe depression Table 14.

Out of the 31 patients who had PSD at baseline, 12 (39\%) showed improvement in the HAM-D score and 19 (61\%) showed no change Figure 9 and Table 15.

Among the 7 PSA patients followed up, 3 (42\%) patients were found to be normal, $1(14 \%)$ with mild depression, $3(42 \%)$ with moderate anxiety Figure 9 and Table 16.

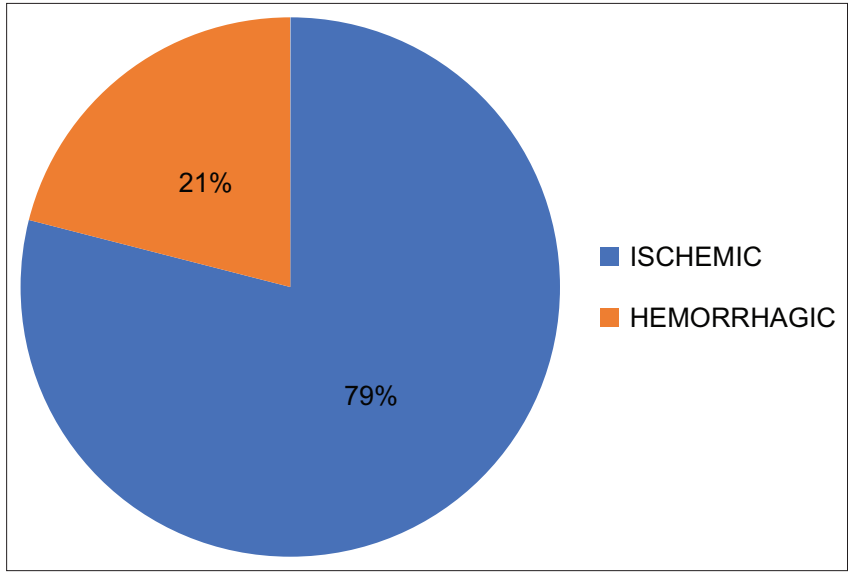

Fig. 1: Distribution of patients based on type of stroke

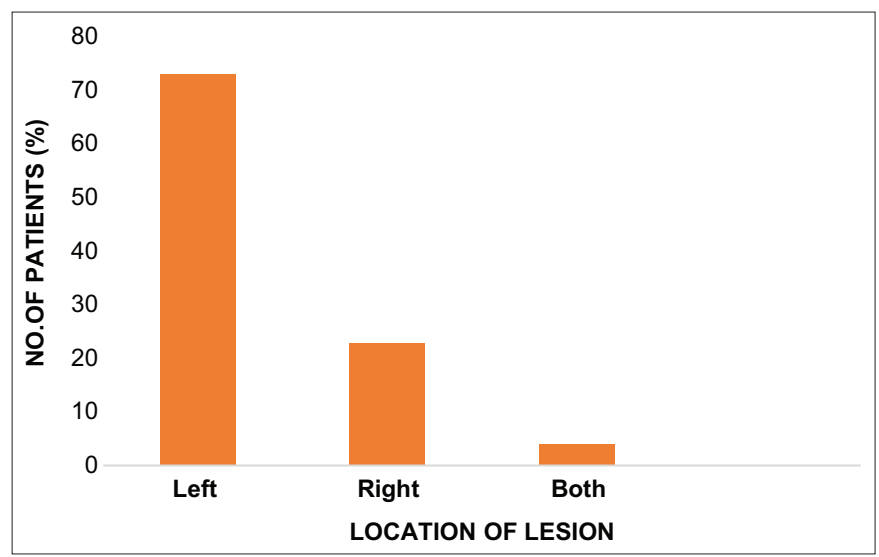

Fig. 2: Distribution based on location of lesion

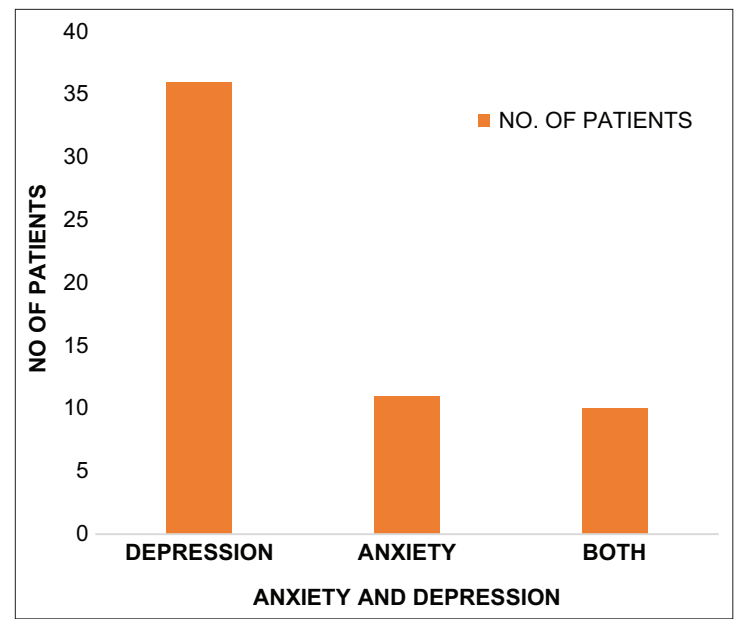

Fig. 3: Distribution based on prevalence of anxiety and depression

Out of the seven patients who had PSD at baseline, 4 (57\%) showed improvement in the HAM-A score and 3 (43\%) showed no change Table 17.

Among the post-stroke depressed and anxiety patients, most of them had mild QOL followed by moderate QOL according the SAQOL scores Figure 10 and Table 18.

Out of the 32 patients followed up, SAQOL scores compared to the baseline- 12 (37\%) showed improved QOL, 15 (47\%) had no change and in $5(16 \%)$ patients the QOL decreased Table 19. 


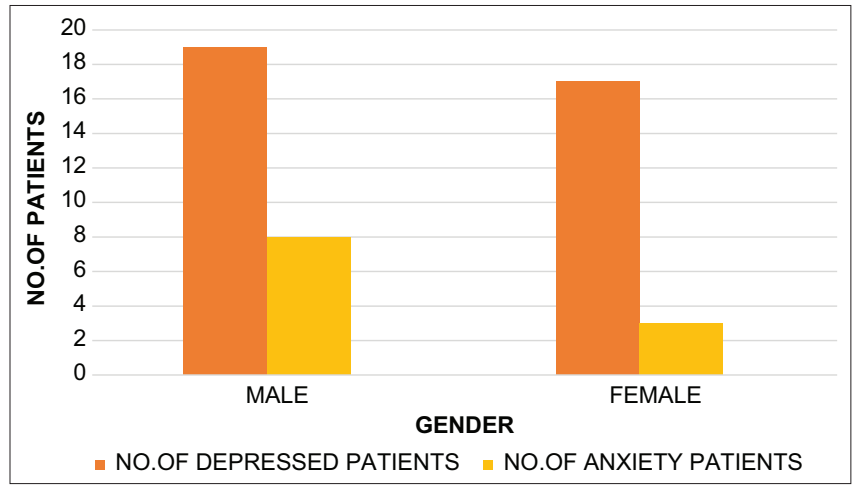

Fig. 4: Correlation between gender and depression and anxiety

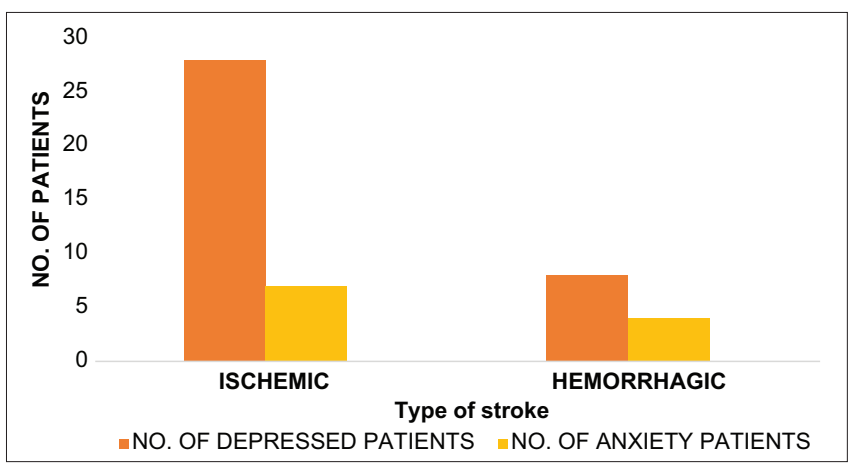

Fig. 5: Correlation between type of stroke, depression and anxiety

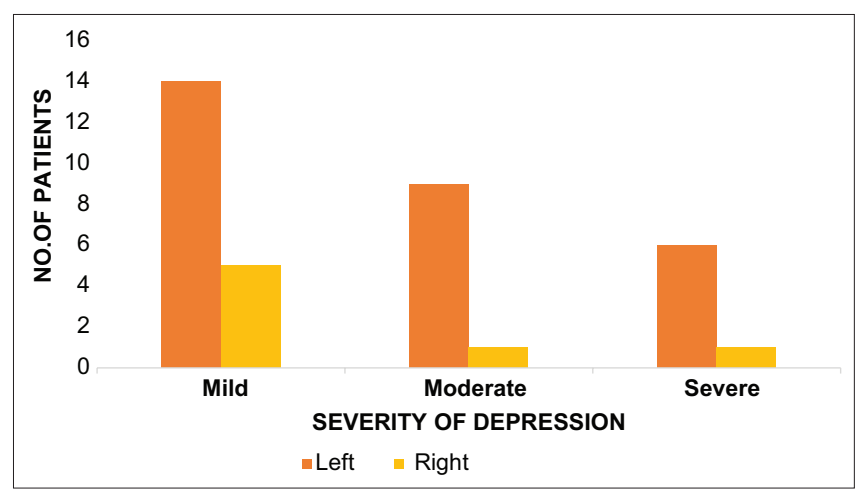

Fig. 6: Correlation between location of lesion and depression

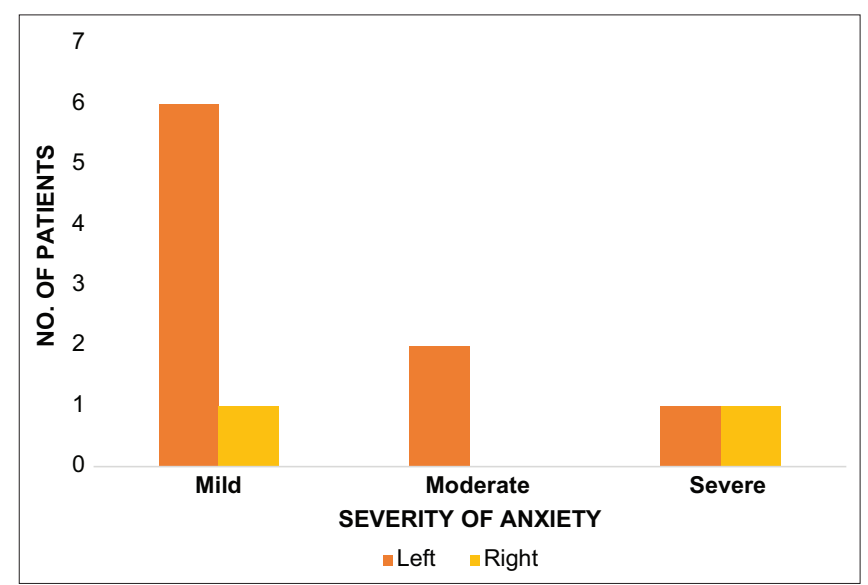

Fig. 7: Correlation between location of lesion and anxiety

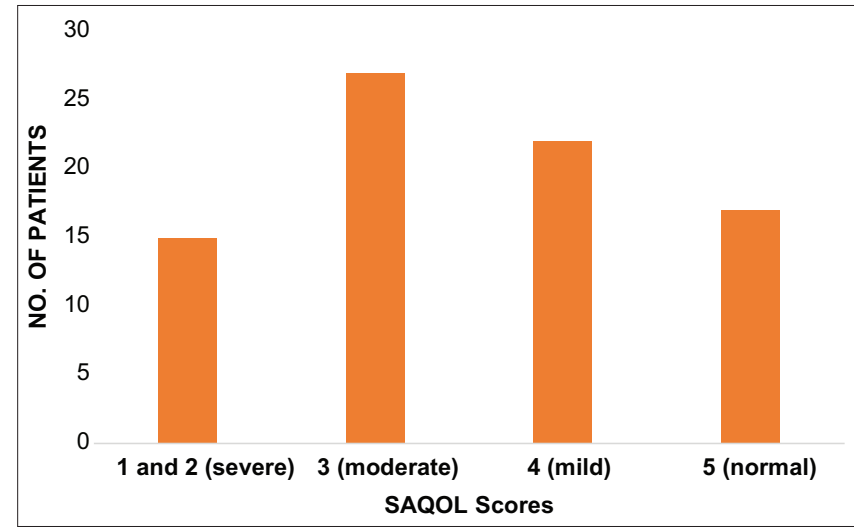

Fig. 8: Distribution based on stroke and aphasia quality of life scores

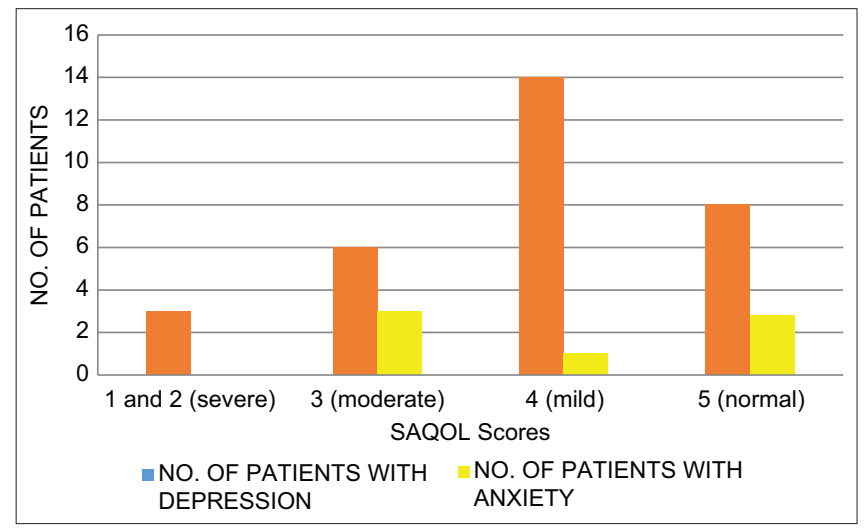

Fig. 9: Stroke and aphasia quality of life responses of patients with depression and/anxiety

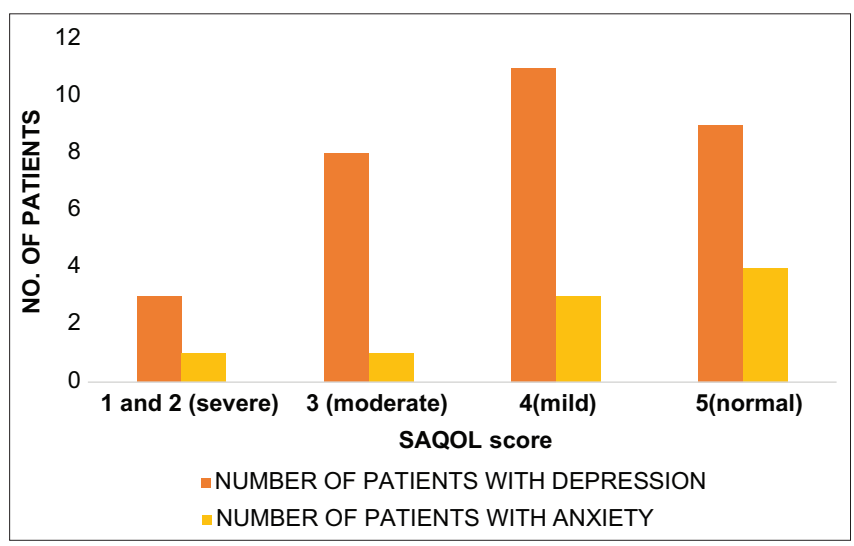

Fig. 10: Stroke and aphasia quality of life responses of patients with depression and/or anxiety at follow-up

\section{DISCUSSION}

The present study was conducted among the students and faculties of Bapuji Pharmacy College, Davanagere for a period of 6 months. The aim of this study was to investigate the prevalence of depression and anxiety in post-stroke patients, the relationship between lesion location and type of stroke with the occurrence of depression or anxiety, assess the comorbidity and provide patient counselling. During the study period, a total of 81 cases of stroke were monitored prospectively. 
Table 1: Demographic characteristics of the subjects

\begin{tabular}{lll}
\hline Characteristics & No. of Subjects $(\mathbf{n = 8 1})$ & Percentage \\
\hline $\begin{array}{l}\text { Gender } \\
\text { Male }\end{array}$ & 54 & 67 \\
Female & 27 & 33 \\
Age & & \\
$<20$ & 0 & 0 \\
$21-30$ & 1 & 1 \\
$31-40$ & 7 & 9 \\
$41-50$ & 10 & 12 \\
$51-60$ & 15 & 18 \\
$61-70$ & 34 & 42 \\
$71-80$ & 9 & 11 \\
$>80$ & 5 & 6 \\
\hline
\end{tabular}

Table 2: Distribution of patients based on comorbid condition

\begin{tabular}{ll}
\hline Comorbid Condition & No. of Patients (n=81) \\
\hline Hypertension & 69 \\
Diabetes & 41 \\
IHD & 18 \\
Respiratory Infections & 12 \\
Dyslipidemia & 9 \\
\hline
\end{tabular}

IHD: Ischemic heart disease

Table 3: Distribution of patients based on the type of stroke

\begin{tabular}{lll}
\hline Type & Number of Patients $(\mathbf{n}=\mathbf{8 1})$ & Percentage \\
\hline Ischemic & 64 & 79 \\
Hemorrhagic & 17 & 21 \\
\hline
\end{tabular}

Table 4: Distribution based on location of lesion

\begin{tabular}{lll}
\hline Side of lesion & No. of patients $(\mathbf{n = 8 1})$ & Percentage \\
\hline Left & 59 & 73 \\
Right & 19 & 23 \\
Both & 3 & 4 \\
\hline
\end{tabular}

Table 5: Distribution based on the prevalence of anxiety and depression

\begin{tabular}{ll}
\hline Parameter & No. of patients $(\mathbf{n = 8 1})$ \\
\hline Depression & 36 \\
Anxiety & 11 \\
Both & 10 \\
None & 24 \\
\hline
\end{tabular}

Table 6: Distribution based on severity of depression

\begin{tabular}{lll}
\hline Severity & No. of patients $(\mathbf{n = 8 1 )}$ & Percentage \\
\hline Normal & 45 & 56 \\
Mild & 19 & 23 \\
Mild-moderate & 10 & 12 \\
Severe & 7 & 9 \\
\hline
\end{tabular}

Table 7: Distribution based on the severity of anxiety

\begin{tabular}{lll}
\hline Severity & No. of patients $(\mathbf{n = 8 1})$ & Percentage \\
\hline Normal & 70 & 86 \\
Mild & 7 & 6 \\
Moderate & 2 & 3 \\
Severe & 2 & 3 \\
\hline
\end{tabular}

Table 8: Correlation between gender and depression and anxiety

\begin{tabular}{lll}
\hline Gender & $\begin{array}{l}\text { No. of depressed } \\
\text { patients }(\mathbf{n}=\mathbf{3 6})\end{array}$ & $\begin{array}{l}\text { No. of anxiety } \\
\text { patients }(\mathbf{n}=\mathbf{1 1})\end{array}$ \\
\hline Male & 19 & 8 \\
Female & 17 & 3 \\
\hline
\end{tabular}

Table 9a: Correlation between type of stroke, depression and anxiety

\begin{tabular}{lll}
\hline Type of stroke & $\begin{array}{l}\text { No. of depressed } \\
\text { patients }(\mathbf{n = 3 6 )}\end{array}$ & $\begin{array}{l}\text { No. of anxiety } \\
\text { patients }(\mathbf{n}=\mathbf{1 1})\end{array}$ \\
\hline Ischemic & 28 & 7 \\
Hemorrhagic & 8 & 4 \\
\hline
\end{tabular}

Table 9b: Test statistics

\begin{tabular}{|c|c|c|c|}
\hline Parameter & $\begin{array}{l}\text { HAM } \\
\text { D-stroke type }\end{array}$ & $\begin{array}{l}\text { HAM } \\
\text { A-stroke type }\end{array}$ & $\begin{array}{l}\text { SAQOL score- } \\
\text { stroke type }\end{array}$ \\
\hline $\mathrm{Z}$ & -7.487 & -8.119 & -6.765 \\
\hline Sig. (2-tailed) & 0.000 & 0.000 & 0.000 \\
\hline
\end{tabular}

HAM: Hamilton, SAQOL: stroke and aphasia quality of life

Table 10: Correlation between location of lesion and depression

\begin{tabular}{lll}
\hline $\begin{array}{l}\text { Severity of } \\
\text { depression }\end{array}$ & $\begin{array}{l}\text { Location } \\
\text { of lesion }\end{array}$ & $\begin{array}{l}\text { No. of patients } \\
\text { (n=36) }\end{array}$ \\
\hline Mild & Left & 14 \\
\multirow{2}{*}{ Moderate } & Right & 5 \\
& Left & 9 \\
Severe & Right & 1 \\
& Left & 6 \\
& Right & 1 \\
\hline
\end{tabular}

Table 11a: Correlation between location of lesion and anxiety

\begin{tabular}{lll}
\hline Severity of anxiety & Location of lesion & No. of patients $(\mathbf{n = 1 1})$ \\
\hline Mild & Left & 6 \\
\multirow{3}{*}{ Moderate } & Right & 1 \\
& Left & 2 \\
Severe & Right & 0 \\
& Left & 1 \\
& Right & 1 \\
\hline
\end{tabular}

Table 11b: Test statistics

\begin{tabular}{llll}
\hline Parameter & $\begin{array}{l}\text { HAM D-location } \\
\text { of lesion }\end{array}$ & $\begin{array}{l}\text { HAM A-location } \\
\text { of lesion }\end{array}$ & $\begin{array}{l}\text { Aphasia-location } \\
\text { of lesion }\end{array}$ \\
\hline $\mathrm{Z}$ & $-1.393^{\mathrm{b}}$ & $-0.642^{\mathrm{c}}$ & $-2.762^{\mathrm{b}}$ \\
Sig. & 0.164 & 0.521 & 0.006 \\
$(2$-tailed) & & & \\
\hline \multicolumn{2}{l}{ HAM: Hamilton, SAQOL: stroke and aphasia quality of life }
\end{tabular}

Table 12: Distribution based on SAQOL scores

\begin{tabular}{ll}
\hline SAQOL scores & Number of patients $(\mathbf{n = 8 1})$ \\
\hline 1 and 2 (severe) & 15 \\
3 (moderate) & 27 \\
4 (mild) & 22 \\
5 (normal) & 17 \\
\hline SAQOL: Stroke and aphasia quality of life &
\end{tabular}


Table 13a: SAQ0L responses of patients with depression and/ or anxiety

\begin{tabular}{lll}
\hline SAQOL scores & $\begin{array}{l}\text { No. of patients with } \\
\text { depression }(\mathbf{n}=\mathbf{3 6})\end{array}$ & $\begin{array}{l}\text { No. of patients with } \\
\text { anxiety }(\mathbf{n}=\mathbf{1 1})\end{array}$ \\
\hline 1 and 2 (severe) & 6 & 8 \\
3 (moderate) & 15 & 1 \\
4 (mild) & 11 & 1 \\
5 (normal) & 4 & 1 \\
\hline
\end{tabular}

SAQOL: Stroke and aphasia quality of life

Table 13b: Test Statistics

\begin{tabular}{lll}
\hline Parameter & HAM D - SAQOL score & HAM A - SAQOL score \\
\hline Z & $-4.942^{\mathrm{b}}$ & $-6.739^{\mathrm{b}}$ \\
Sig. (2-tailed) & 0.000 & 0.000 \\
\hline
\end{tabular}

HAM: Hamilton, SAQOL: stroke and aphasia quality of life

Table 14: Severity of depression during follow up

\begin{tabular}{ll}
\hline Severity & No. of patients $(\mathbf{n}=\mathbf{3 1})$ \\
\hline Normal & 8 \\
Mild & 14 \\
Moderate & 6 \\
Severe & 3 \\
\hline
\end{tabular}

Table 15: Change in severity of depression during follow-up

\begin{tabular}{ll}
\hline Severity & No. of patients $(\mathbf{n}=\mathbf{3 1})$ \\
\hline Improved & 12 \\
No change & 19 \\
Deteriorated & 0 \\
\hline
\end{tabular}

Table 16: Severity of anxiety during follow up

\begin{tabular}{ll}
\hline Severity & No. of patients $(n=7)$ \\
\hline Normal & 3 \\
Mild & 1 \\
Moderate & 3 \\
Severe & 0 \\
\hline
\end{tabular}

Table 17: Change in severity of anxiety during follow-up

\begin{tabular}{ll}
\hline Severity & No. of patients $(\mathbf{n}=7)$ \\
\hline Improved & 4 \\
No change & 3 \\
Deteriorated & 0 \\
\hline
\end{tabular}

Table 18: SAQOL responses of patients with depression and/or anxiety at follow up

\begin{tabular}{lll}
\hline SAQOL scores & $\begin{array}{l}\text { Number of patients } \\
\text { with depression }(\mathbf{n = 3 1})\end{array}$ & $\begin{array}{l}\text { Number of patients } \\
\text { with anxiety }(\mathbf{n}=7)\end{array}$ \\
\hline 1 and 2 (severe) & 3 & 1 \\
3 (moderate) & 8 & 1 \\
4 (mild) & 11 & 3 \\
5 (normal) & 9 & 2 \\
\hline
\end{tabular}

SAQOL: stroke and aphasia quality of life

Sudden occurrence of neurological deficits might cause depression and anxiety in stroke patients. Assessment of PSD and PSA was done by conducting HAM A, HAM D interview, and SAQOL questionnaire, along with the deliverance of bedside patient education. The study represents
Table 19: Change in SAQOL score at follow up

\begin{tabular}{ll}
\hline SAQOL score & Number of patients $(\mathbf{n}=\mathbf{3 2})$ \\
\hline Improved & 12 \\
Same & 15 \\
Decreased & 5 \\
\hline
\end{tabular}

SAQOL: stroke and aphasia quality of life

a significant contribution to literature on the significance of PSD and PSA. It was found that symptoms of anxiety and depression were predominant after the stroke episode. By estimating the prevalence of PSD and PSA among the stroke survivors that PSD affected 44\%. Our results were also consistent with the previous studies conducted by De Ryck et al. [5] and Karamchandani et al. [6] Prevalence of anxiety was $14 \%$ in stroke patients which is similar to the study conducted by De Wit et al. [7].

Out of 81 subjects enrolled in the study, 54 patients were males and 27 were females. The gender distribution shows predominant male involvement. This observation was similar to the study conducted by Schöttke and Giabbiconi [8] and Habibi-Koolaee et al. [9]. The present study revealed that the patients belonging to the age group 61-70 years were more predominant which is in compliance with the outcomes of the study conducted by Schöttke and Giabbiconi [8].

In our study, hypertension (85\%), diabetes mellitus (50.6\%), and IHD $(22 \%)$ were the major comorbidities among the post-stroke patients. This was in accordance with the findings of the study conducted by Habibi-Koolaee et al. [10]. In our study, the prevalence of depression and anxiety were mostly observed in post-ischemic stroke patient (79\%), similar results were observed in the study conducted by Karmachandini et al. [6] and De Wit et al. [7].

Out of 36 post-stroke patients with depression and 11 with anxiety, $80.55 \%$ and $82 \%$ of patients had left side lesions, respectively. This observation was similar to a study conducted by Rajashekar et al. [11] and Barker-Collo [12]

Out of 36 patients with symptoms of depression, $23 \%$ of patients showed mild depression, moderate depression was seen in $12 \%$ and $9 \%$ of severe depression. Moreover, among 11 patients showing the symptoms of anxiety, $6 \%$ patients showed mild anxiety, $3 \%$ showed moderate anxiety, and $3 \%$ patients' severe anxiety which is similar to the study conducted by Fang et al. [3]

The number of PSD and anxiety were found to be more common in male patients, in contrast with the study conducted by Paradiso and Robinson [13].

In terms of stroke-related factors, ischemic stroke type was found statistically associated with depression and anxiety, and also significant relation was observed between lesion location of stroke (left side) and depression or anxiety corresponding to the study conducted by Tsehayneh and Tafesse [14] and Leppävuori et al. [15].

By comparison of scores within baseline of depression, anxiety, stroke severity, and aphasia; aphasia is related to the left side location of lesion, contrasting to the study conducted by Pedersen et al. [16] but HAM D and HAM A scores did not show any significant relationship $(\mathrm{p} \leq 0.05)$. Among the 81 stroke patients, the majority of them had moderate QOL followed by mild, normal, and severe based on the SAQOL scores corresponding to the study conducted by Ramos-Lima et al. [17].

Moderate QOL was predominant in post-stroke depressed patients, whereas severe SAQOL score is seen in PSA patients, consistent to the study conducted by Khedr et al. [4] and Tang et al. [18], respectively. SAQOL scores of baseline patients were compared with HAM D and HAM A to assess if the degree of decline in QOL patients with depression 
and anxiety. The results of the test showed a positive effect to moderate QOL ( $\leq 0.05)$

Out of 31 post-stroke depressed patients who was followed up, 25\% patients were found to be normal, $45 \%$ with mild depression, $19 \%$ with moderate, and $9 \%$ with severe depression. Moreover, among seven PSA patients followed up, $42 \%$ patients were found to be normal, $14 \%$ with mild anxiety, $42 \%$ with moderate anxiety corresponding to the study conducted by Fang et al. [3]

Out of the 31 patients who had PSD at baseline, 39\% showed improvement in the HAM-D score and $61 \%$ showed no change and out of the seven patients who had PSA at baseline, 57\% showed improvement in the HAM-A score and $43 \%$ showed no change. In PSD and anxiety patients, most of them had mild QOL followed by moderate QOL according to the SAQOL scores. Out of 32 patients followed up, SAQOL scores compared to the baseline $37 \%$ showed improved QOL, $47 \%$ had no change and in $16 \%$ patients, the QOL decreased.

Out of 36 patients showing depressive symptoms, 31 patients were followed up. (68\%) of the population showed significant symptoms of depression at follow-up. Out of 11 patients showing anxiety symptoms, seven patients were followed up. (57\%) of the population showed significant symptoms of anxiety at follow-up. On the other hand, 38.7\% of the participants who showed depressive symptoms at baseline and $57 \%$ of the participants had improved scores during the follow-up.

To sum up, factors contributing to increased risk of depression and anxiety after stroke include age, sex, co-morbidities, location of lesion, and type of stroke. Early detection of depression and anxiety symptoms may facilitate functional recovery and improve QOL in stroke patients if careful evaluation of PSD and PSA is integrated into clinical care of stroke patients.

\section{CONCLUSION}

The results of our study show the prevalence of PSD and Anxiety and its correlation with left-sided lesions and ischemic type of stroke. Common comorbidities associated with PSD and PSA were found to be hypertension and diabetes mellitus. Though the scores for both HAM-D and HAM-A had improved during follow-up, the patients were still found to have depression and/or anxiety.

A clear understanding of the relationship between depression and anxiety with the mentioned correlates post-stroke will assist clinicians in early identification of patients at the highest risk for mood disturbance and those likely to benefit from treatment interventions.

\section{ACKNOWLEDGMENT}

We are grateful to our Principal, HOD, and Faculties of Pharmacy Practice Department of Bapuji Pharmacy College for their continuous support and encouragement.

\section{CONFLICT OF INTEREST}

There is no conflict of interest between the authors.

\section{REFERENCES}

1. Robinson RG, Jorge RE. Post-stroke depression:A review. Am J Psychiatry 2016;173:221-31.

2. Vermani M, Marcus M, Katzman MA. Rates of detection of mood and anxiety disorders in primary care:A descriptive, cross-sectional study. Prim Care Companion CNS Disord 2011;13:PCC.10m01013.

3. Fang Y, Mpofu E, Athanasou J. Reducing depressive or anxiety symptoms in post-stroke patients: Pilot trial of a constructive integrative psychosocial intervention. Int J Health Sci 2017;11:53.

4. Khedr EM, Abdelrahman AA, Desoky T, Zaki AF, Gamea A. Poststroke depression: Frequency, risk factors, and impact on quality of life among 103 stroke patients hospital-based study. Egypt J Neurol Psychiatry Neurosurg 2020;56:1-8.

5. De Ryck A, Brouns R, Fransen E, Geurden M, Van Gestel G, Wilssens I, et al.A prospective study on the prevalence and risk factors of poststroke depression. Cerebrovasc Dis Extra 2013:3:1-3.

6. Karamchandani RR, Vahidy F, Bajgur S, Vu KY, Choi HA, Hamilton RK, et al. Early depression screening is feasible in hospitalized stroke patients. PLoS One 2015;10:e0128246.

7. De Wit L, Putman K, Baert I, Lincoln NB, Angst F, Beyens H, et al. Anxiety and depression in the first six months after stroke.A longitudinal multicentre study. Disabil Rehabil 2008;30:1858-66.

8. Schöttke H, Giabbiconi CM. Post-stroke depression and post-stroke anxiety: Prevalence and predictors. Int Psychogeriatr 2015;27:1805-12.

9. Habibi-Koolaee M, Shahmoradi L, Kalhori SR, Ghannadan H, Younesi E. Prevalence of stroke risk factors and their distribution based on stroke subtypes in Gorgan:A retrospective hospital-based study 2015-2016. Neurol Res Int 2018;2018:2709654.

10. Luijendijk HJ, Stricker BH, Wieberdink RG, Koudstaal PJ, Hofman A, Breteler MM, et al. Transient ischemic attack and incident depression. Stroke 2011;42:1857-61.

11. Rajashekaran P, Pai K, Thunga R, Unnikrishnan B. Post-stroke depression and lesion location:A hospital based cross-sectional study. Indian J Psychiatry 2013;55:343.

12. Barker-Collo SL. Depression and anxiety 3 months post stroke: Prevalence and correlates. Arch Clin Neuropsychol 2007;22:519-31.

13. Paradiso S, Robinson RG. Gender differences in poststroke depression.J Neuropsychiatry Clin Neurosci 1998;10:41-7.

14. Tsehayneh F, Tafesse A. High prevalence of poststroke depression in ischemic stroke patients in Ethiopia. Neurol Res Int 2020;2020:8834299.

15. Leppävuori A, Pohjasvaara T, Vataja R, Kaste M, Erkinjuntti T. Generalized anxiety disorders three to four months after ischemic stroke. Cerebrovasc Dis 2003:16:257-64

16. Pedersen PM, Jørgensen HS, Nakayama H, Raaschou HO, Olsen TS. Aphasia in acute stroke: Incidence, determinants, and recovery. Ann Neurol 1995;38:659-66.

17. Ramos-Lima MJ, Brasileiro ID, Lima TL, Braga-Neto P. Quality of life after stroke: Impact of clinical and sociodemographic factors. Clinics 2018;73:e418.

18. Tang WK, Lau CG, Mok V, Ungvari GS, Wong KS. Impact of anxiety on health-related quality of life after stroke:A cross-sectional study. Arch Phys Med Rehabil 2013;94:2535-41. 